\title{
Effect of exercise immersion experience on health promotion and lifelong physical education of high school students in sports club activities
}

\author{
Young Jun Ko' ${ }^{1}$, Jun-Su Kim ${ }^{2 * *}$ \\ ${ }^{1}$ Major in Sport Service Practice, College of Welfare Convergence, Kangnam University, Yongin, Korea \\ ${ }^{2}$ Department of Sports and Outdoors, College of Bio Convergence, Eulji University, Seongnam, Korea
}

The purpose of this study was to investigate the impact of high school students' athletic commitment, health promotion education, and lifelong sports activities. To this end, the researcher searched for research subjects of 397 high school students residing in Seoul in 2019. As a result of the analysis, the following conclusions were drawn. First, the effect of exercise commitment on sports health promotion education was investigated. Looking at the activities of high school students, their commitment to behavior has had a profound impact on their health responsibilities and relationships. Second, the study also investigated the impact of athletic commitment to lifelong sports of sports activities in high school students and found that cognitive and behavioral commitment had a significant impact on lifelong sports. Finally, as a result of investigating the impact of health promotion education on lifelong sports of high school student sports activities, it was found that health responsibility and relationships have a great influence on lifelong sports.

Keywords: High school student, Exercise commitment, Sports activity, Health promotion education, Lifetime sports

\section{INTRODUCTION}

The current health policy sets out people's current physical and athletic abilities and provides guidance on athletic and sports activities. Adolescence is a time when a lot of physical and mental changes take place, but the current Korean entrance exam-oriented educational climate has made adolescents prolonged sedentary life, and their mental health is also threatened by lack of movement and academic stress. High school students in Korea have an increasing obesity rate due to lack of physical activity, and are exposed to risk factors related to various health behaviors, such as smoking, drinking alcohol, lack of exercise, stress, and irregular eating habits (Michael and Ben-Zur, 2007).

Lack of physical health has been considered an important cause of future lifestyle-related diseases, including metabolic syndrome, diabetes, or high blood pressure. In previous studies, it has been reported that people with low levels of physical activity have in-

creased body mass index, waist circumference, and body fat mass compared to people with high levels of physical activity (Woolf et al., 2008). Children with higher levels of physical activity have reported better cardiovascular health indicators than children with lower levels of physical activity, and stronger physical activity has been reported to weaken arterial stiffness (Proudfoot et al., 2019).

Nutrition education has a good effect on children's eating habits, and the nutritionist's role is to oversee food preparation and meal planning, as well as to teach nutrition education as a teacher (Nakamura, 2008). Regular physical exercise is an activity with the main ability to maintain and improve physical and mental health (Mayolas-Pi et al., 2017). Satisfaction with physical activity is known to be an important factor in maintaining physical activity, but the factors that influence satisfaction are not well known (Baldwin et al., 2013). These physical activities should not be limited to adolescence throughout life, but should consist of lifelong physical education. Sports activities have attracted the most

${ }^{\star}$ Corresponding author: Jun-Su Kim (D https://orcid.org/0000-0002-7078-4926 Department of Sports and Outdoors, College of Bio Convergence, Eulji University, 553 Sanseong-daero, Sujeong-gu, Seongnam 13135, Korea Email: kjskjs777@hanmail.net

This is an Open Access article distributed under the terms of the Creative Commons Attribution Non-Commercial License (https://creativecommons.org/licenses/by-nc/4.0/) which permits unrestricted non-commercial use, distribution, and reproduction in any medium, provided the original work is properly cited. 
people in recent decades thanks to their ability to maintain and improve their health (Nogueira et al., 2018).

Students who do not have the habit of engaging in sports or sports activities may have lacked motivation. However, they had a high level of positivity for sports or sports activities. Therefore, it is important to be actively engaged in exercise and/or physical activity with a specific purpose in mind (Tamura et al., 2021). Therefore, this study attempted to grasp the perception of health promotion education and lifelong physical education as a result of exercise immersion of high school students participating in sports activities. This is to emphasize the importance of health promotion education through sports activities and to provide basic data for linking sports activities of high school students to lifelong physical education.

\section{MATERIALS AND METHODS}

\section{Subjects}

This study distributed a survey of 450 high school students living in Seoul and participating in sports activities in 2019. All 450 surveys were collected, and a total of 397 questionnaires were used

Table 1. Demographic characteristics of research subjects ( $N=397)$

\begin{tabular}{lc}
\hline Variable & No. $(\%)$ \\
\hline Gender & \\
Boys & $250(63.0)$ \\
Girls & $147(37.0)$ \\
Grade & \\
1st year & $30(7.6)$ \\
2nd year & $152(38.3)$ \\
3 rd year & $215(54.2)$ \\
Years of exercise & \\
Less than 6 mo & $117(29.5)$ \\
6 mo-1 yr & $108(27.2)$ \\
$1-2$ yr & $87(21.9)$ \\
$2-3$ yr & $29(7.3)$ \\
3 yr or more & $56(14.1)$ \\
No. of exercises & \\
1 Time a wk & $48(12.1)$ \\
2 Times a wk & $129(32.5)$ \\
3 Times a wk & $170(42.8)$ \\
4 Times a wk or more & $50(12.6)$ \\
Hours of exercise & \\
2 hr & $51(12.9)$ \\
$3-4$ hr & $205(51.6)$ \\
4 hr or more & $112(28.2)$ \\
\hline
\end{tabular}

for actual analysis, excluding 53 incomplete surveys that were inconsistent or missing content. This experiment was approved by the Research Ethics Committee (2019-145). The characteristics of the participants are shown in Table 1.

\section{Composition of research tools}

This study used a survey questionnaire as a tool for collecting data. The questionnaire consisted of 35 questions in four areas, including questions that measured the general characteristics of high school students, exercise immersion, health promotion education, and connection to lifelong physical education. A 5-point Likert Scale was used for each item, and for the exercise immersion scale, eight measurement questions used in a research by Scanlan et al. (1993) were used after revising. Next, health-promoting lifestyle profile II was partially modified to meet the purpose of this study (Bozo et al., 2009).

\section{Validity and reliability of research tools}

In this study, exploratory factor analysis was performed to verify the validity and reliability of the questionnaire. To verify reliability in Table 2, this study calculated Cronbach's $\alpha$ coefficient to confirm the internal consistency among the questions.

\section{Validity and reliability of exercise immersion}

As a result of exploratory factor analysis of orthogonal rotation through principal component analysis for exercise immersion, the factor load criterion was set to 0.4 or more. To find out the normal distribution of the population and the suitability of the data, the study conducted Bartlett's unit matrix test and the standard suitability Kaiser-Meyer-Olkin (KMO) for each variable. In Table 3, the cumulative rate explaining the two factors of exercise immersion was $70.206 \%$, and Cronbach $\alpha$ was relatively high (0.9090.807), so the exercise immersion scale has both reliability and validity.

Table 2. Reliability test of research tools

\begin{tabular}{llcc}
\hline Variable & \multicolumn{1}{c}{ Subfactors } & $\begin{array}{c}\text { No. of } \\
\text { questions }\end{array}$ & Cronbach $\alpha$ \\
\hline Exercise immersion & $\begin{array}{l}\text { Cognitive immersion } \\
\text { Behavioral immersion }\end{array}$ & 5 & 9.909 \\
Health promotion & Health responsibility & 4 & 0.867 \\
education & Exercise and nutrition & 4 & 0.837 \\
& Self-realization & 4 & 0.892 \\
& Interpersonal relationship & 3 & 0.764 \\
Connection to lifelong & Single factor & 5 & 0.853 \\
physical education & & &
\end{tabular}


Table 3. Factor analysis of exercise immersion

\begin{tabular}{lcc}
\hline Question & Cognitive immersion & Behavioral immersion \\
\hline Exercise immersion 6 & 0.844 & 0.280 \\
Exercise immersion 4 & 0.810 & 0.319 \\
Exercise immersion 5 & 0.802 & 0.351 \\
Exercise immersion 9 & 0.760 & 0.314 \\
Exercise immersion 3 & 0.701 & 0.427 \\
Exercise immersion 7 & 0.242 & 0.861 \\
Exercise immersion 10 & 0.277 & 0.761 \\
Exercise immersion 2 & 0.390 & 0.752 \\
Exercise immersion 1 & 0.424 & 0.692 \\
Exercise immersion 8 & 0.484 & 0.536 \\
Eigenvalue & 3.785 & 3.236 \\
Variance (\%) & 37.845 & 32.361 \\
Cumulative (\%) & 37.845 & 70.206
\end{tabular}

Kaiser-Meyer-Olkin $=0.923, \chi^{2}=2,622.374, d f=45$, sig $=0.000$.

\section{Validity and reliability of health promotion education}

As a result of orthogonal rotation exploratory factor analysis through principal component analysis for health promotion education, the factor load criterion was set to be 0.4 or higher. To find out the normal distribution of the population and the suitability of the data, the study conducted Bartlett's unit matrix test and the standard suitability KMO for each variable. In Table 4, the cumulative rate explaining the four factors of health promotion education is $70.152 \%$, and Cronbach's $\alpha$ is relatively high at $0.892-0.764$, so the health promotion education scale has both reliability and validity.

\section{Validity and reliability of the awareness of connection to lifelong physical education}

As a result of orthogonal rotation exploratory factor analysis through principal component analysis for health promotion education, the factor load criterion was set to be 0.4 or more. To find out the normal distribution of the population and the suitability of the data, the study conducted Bartlett's unit matrix test and the standard suitability KMO for each variable. In the Table 5, the cumulative ratio explaining a single factor linked to lifelong physical education was $63.477 \%$, and Cronbach $\alpha$ is relatively high at 0.853 , so the lifelong physical education scale has both reliability and validity.

\section{RESULTS}

\section{Correlation analysis}

In this study, a correlation analysis was performed to verify the relationship between the scales of each subfactor whose uniformity was proven, and the results are shown in Table 6. As a result of
Table 4. Factor analysis of health promotion education

\begin{tabular}{lcccc} 
Question & $\begin{array}{c}\text { Health } \\
\text { responsibility }\end{array}$ & $\begin{array}{c}\text { Exercise } \\
\text { and } \\
\text { nutrition }\end{array}$ & $\begin{array}{c}\text { Self- } \\
\text { realization }\end{array}$ & $\begin{array}{c}\text { Interpersonal } \\
\text { relationship }\end{array}$ \\
\hline Health promotion education 14 & 0.847 & 0.129 & 0.152 & 0.072 \\
Health promotion education 15 & 0.816 & 0.119 & 0.108 & 0.174 \\
Health promotion education 12 & 0.766 & 0.028 & 0.201 & 0.205 \\
Health promotion education 13 & 0.597 & 0.230 & 0.060 & 0.395 \\
Health promotion education 6 & 0.160 & 0.867 & 0.165 & 0.190 \\
Health promotion education 7 & 0.146 & 0.843 & 0.191 & 0.177 \\
Health promotion education 5 & 0.141 & 0.839 & 0.247 & 0.137 \\
Health promotion education 8 & 0.045 & 0.628 & 0.128 & 0.541 \\
Health promotion education 3 & 0.347 & 0.143 & 0.773 & 0.205 \\
Health promotion education 1 & 0.081 & 0.292 & 0.618 & 0.283 \\
Health promotion education 2 & 0.598 & 0.135 & 0.614 & 0.008 \\
Health promotion education 4 & 0.058 & 0.410 & 0.587 & 0.310 \\
Health promotion education 10 & 0.176 & 0.204 & 0.275 & 0.788 \\
Health promotion education 11 & 0.387 & 0.193 & 0.178 & 0.619 \\
Health promotion education 9 & 0.290 & 0.329 & 0.311 & 0.536 \\
\hline Eigenvalue & 3.148 & 3.126 & 2.125 & 2.123 \\
Variance (\%) & 20.989 & 20.842 & 14.170 & 14.152 \\
Cumulative(\%) & 20.989 & 41.830 & 56.000 & 70.152 \\
\hline
\end{tabular}

Kaiser-Meyer-0lkin $=0.919, \chi^{2}=3,213.674, d f=105$, sig $=0.000$.

Table 5. Factor analysis of the awareness of connection to lifelong physical education

\begin{tabular}{lc}
\hline Question & Single factor \\
\hline Awareness of connection to lifelong physical education 3 & 0.832 \\
Awareness of connection to lifelong physical education 2 & 0.828 \\
Awareness of connection to lifelong physical education 4 & 0.812 \\
Awareness of connection to lifelong physical education 1 & 0.780 \\
Awareness of connection to lifelong physical education 5 & 0.727 \\
Eigenvalue & 3.174 \\
Variance (\%) & 63.477 \\
Cumulative (\%) & 63.477 \\
\hline
\end{tabular}

Kaiser-Meyer-Olkin $=0.841, \chi^{2}=832.297, d f=10$, sig $=0.000$.

the correlation analysis, Pearson correlation coefficient was $0.242-$ 0.753 , which was less than the multicollinearity criterion of 0.80 , so there was no problem with weighted collinearity.

\section{The effect of exercise immersion experience on health promotion education}

Table 7 shows the results of analysis of high school students' exercise immersion experience in sports activities for health promotion education. Among the factors of exercise immersion through participation in sports activities, behavior immersion $(\beta=0.463)$ had a significant effect on health responsibility, a subfactor of 
Table 6. Correlation analysis among exercise immersion experience, health promotion education, and the awareness of connection to lifelong physical education

\begin{tabular}{lcccccc}
\hline Variable & 1 & 2 & 3 & 4 & 5 & 6 \\
\hline Cognitive immersion & 1 & & & & & \\
Behavioral immersion & $0.753^{* *}$ & 1 & & & & \\
Health responsibility & $0.287^{* *}$ & $0.417^{* *}$ & 1 & & & \\
Exercise and nutrition & $0.289^{* *}$ & $0.242^{* *}$ & $0.378^{* *}$ & 1 & & \\
Self-realization & $0.265^{* *}$ & $0.326^{* *}$ & $0.578^{* *}$ & $0.592^{* *}$ & 1 & 1 \\
Interpersonal relationship & $0.328^{* *}$ & $0.366^{* *}$ & $0.573^{* *}$ & $0.614^{* *}$ & $0.651^{* *}$ & $0.373^{* *}$ \\
Connection to lifelong physical education & $0.550^{* *}$ & $0.590^{* *}$ & $0.426^{* *}$ & $0.263^{* *}$ & $0.349^{* *}$ & 1 \\
\hline
\end{tabular}

${ }^{* *} P<0.01$.

Table 7. The effects of exercise immersion experience on health promotion education

\begin{tabular}{|c|c|c|c|c|c|c|c|c|}
\hline \multirow{2}{*}{ Variable } & \multicolumn{2}{|c|}{ Health responsibility } & \multicolumn{2}{|c|}{ Exercise and nutrition } & \multicolumn{2}{|c|}{ Self-realization } & \multicolumn{2}{|c|}{ Interpersonal relationship } \\
\hline & $\beta$ & $t$ & $\beta$ & $t$ & $\beta$ & $t$ & $\beta$ & $t$ \\
\hline Cognitive immersion & -0.062 & -0.886 & 0.246 & $3.355^{* * *}$ & 0.045 & 0.621 & 0.120 & 1.693 \\
\hline Behavioral immersion & 0.463 & $6.671^{* * *}$ & 0.057 & 0.785 & 0.292 & $4.038^{* * *}$ & 0.276 & $3.885^{* * *}$ \\
\hline$F$ & \multicolumn{2}{|c|}{41.973} & \multicolumn{2}{|c|}{18.272} & \multicolumn{2}{|c|}{23.610} & \multicolumn{2}{|c|}{32.132} \\
\hline$R^{2}$ & \multicolumn{2}{|c|}{0.176} & \multicolumn{2}{|c|}{0.080} & \multicolumn{2}{|c|}{0.107} & \multicolumn{2}{|c|}{0.140} \\
\hline
\end{tabular}

${ }^{* * *} P<0.001$.

Table 8. Effects of exercise immersion experience on connection to lifelong physical education

\begin{tabular}{lcc}
\hline \multirow{2}{*}{ Variable } & \multicolumn{2}{c}{ Connection to lifelong physical education } \\
\cline { 2 - 3 } & $\beta$ & $t$ \\
\hline Cognitive immersion & 0.245 & $4.039^{* * *}$ \\
Behavioral immersion & 0.406 & $6.703^{* * *}$ \\
$F$ & & 117.665 \\
$R^{2}$ & & 0.374 \\
\hline
\end{tabular}

${ }^{* * *} P<0.001$.

health promotion education, and the regression explanatory power was $17.6 \%$. Cognitive immersion $(\beta=0.246)$ had a significant effect on exercise and nutrition with $8.0 \%$ regression explanatory power, and behavioral immersion $(\beta=0.292)$ had a significant effect on self-realization with $10.7 \%$ regression explanatory power. Lastly, behavioral immersion $(\beta=0.276)$ had a significant effect on interpersonal relationship with $14.0 \%$ regression explanatory power. In other words, the higher the behavioral immersion of exercise immersion, the higher the health responsibility, self- realization, and interpersonal relationships, whereas the higher the cognitive immersion, the higher the exercise and nutrition.

The effects of exercise immersion experience on the awareness of lifelong physical education awareness connection

Table 8 is the result of analyzing the effect of high school stu-
Table 9. The effects of health promotion education on the awareness of connection to lifelong physical education

\begin{tabular}{lcc}
\hline \multirow{2}{*}{ Variable } & \multicolumn{2}{c}{ Connection to lifelong physical education } \\
\cline { 2 - 3 } & $\beta$ & $t$ \\
\hline Health responsibility & 0.292 & $5.018^{* * *}$ \\
Exercise and nutrition & 0.019 & 0.315 \\
Self-realization & 0.074 & 1.122 \\
Interpersonal relationship & 0.146 & $2.164^{*}$ \\
$F$ & & 25.999 \\
$R^{2}$ & & 0.210 \\
\hline
\end{tabular}

${ }^{*} P<0.05$. ${ }^{* *} P<0.001$.

dents' exercise immersion experience on the perception of association with lifelong physical education in sports activities. Among the factors of exercise immersion, cognitive immersion $(\beta=0.245)$ and behavioral immersion $(\beta=0.406$ ) had a significant effect on the perception, and the regression explanatory power was $37.4 \%$. In other words, the higher cognitive immersion and behavioral immersion, which are the subfactors of exercise immersion, the higher the awareness of the association with lifelong physical education is.

The effects of health promotion education on the awareness of connection to lifelong physical education

Table 9 is the results of analyzing the effects of health promotion education on the awareness of connection to lifelong physical 
education. Among the factors of health promotion education, health responsibility $(\beta=0.292)$ and interpersonal relationship ( $\beta=0.146)$ had a significant effect on the students' perception, and the regression explanatory power was $21.0 \%$. In other words, the higher the health responsibility and interpersonal relationship, which are the subfactors of health promotion education, the higher the awareness of the association with lifelong physical education.

\section{DISCUSSION}

The intense relationship between adolescent individuals and peer groups points to the importance of planning prevention and intervention programs for risky behaviors. In addition to individual counseling, interventions may be more effective if group-level programs are conducted within factions rather than in school classes. It suggests that interventions can successfully achieve their goals if performed individually for each gender, and highlights the factors that have a discriminatory impact between boys and girls (Michael and Ben-Zur, 2007).

It has been shown that people with higher average levels of positive experiences and lower levels of thinking about the negative aspects of exercise are more likely to report higher levels of satisfaction, and perceived progress towards positive experiences and goals within the individual (Baldwin et al., 2013). Without exercise for 2 weeks, depression, confusion, anger, and fatigue increased, as well as a slight increase in $\beta$-endorphin, resulting in decreased vitality (Antunes et al., 2016). Exercise has been shown to improve sleep efficiency and duration, especially in populations suffering from disease (Dolezal et al., 2017). Most of the people who were aware of their health were worried about their eating habits and some about their physical activity.

The purpose of this study was to investigate the effect of high school students participating in sports activities on the relationship between exercise immersion experience, health promotion education, and lifelong sports connection perception. To achieve the purpose of this study, 397 high school students living in Seoul and participating in sports activities were selected as the subject of the study, and data collection and analysis were conducted using a questionnaire to draw the following conclusions.

First, as a result of examining the effect of exercise immersion experience of high school students participating in sports activities on health promotion education, behavioral immersion was found to have a significant effect on health responsibility, self-realization, and interpersonal relationships. It was found to have a significant effect. In other words, the higher the behavioral immersion of exercise immersion, the higher the health responsibility, self-realization, and interpersonal relationships, and the higher the cognitive immersion, the higher the exercise and nutrition.

Second, as a result of examining the effect of the sports immersion experience of high school students participating in sports activities on the perception of lifelong sports connection, both cognitive immersion and behavioral immersion had a significant effect on the perception of lifelong sports connection. In other words, the higher the cognitive immersion and behavioral immersion, which are the subfactors of exercise immersion, the higher the awareness of lifelong sports connection.

Third, as a result of examining the effect of health promotion education through exercise immersion experience of high school students participating in sports activities on the perception of lifelong sports connection, it was found that health responsibility and interpersonal relationships had a significant effect on lifelong sports connection. In other words, the higher the health responsibility and interpersonal relationships of health promotion education, the higher the awareness of lifelong sports connection increases.

Thus, the exercise immersion experienced by high school students engaging in sports activities allows them to have a desirable perception of their health responsibilities. Since self-actualization and stable interpersonal relationships can lead to lifelong physical education through health promotion education, it is necessary to provide continuous physical education in high school.

\section{CONFLICT OF INTEREST}

No potential conflict of interest relevant to this article was reported.

\section{ACKNOWLEDGMENTS}

The authors received no financial support for this article.

\section{REFERENCES}

Antunes HK, Leite GS, Lee KS, Barreto AT, Santos RV, Souza Hde S, Tufik S, de Mello MT. Exercise deprivation increases negative mood in exercise-addicted subjects and modifies their biochemical markers. Physiol Behav 2016:156:182-190.

Baldwin AS, Baldwin SA, Loehr VG, Kangas JL, Frierson GM. Elucidating satisfaction with physical activity: An examination of the day-to- 
day associations between experiences with physical activity and satisfaction during physical activity initiation. Psycho Health 2013;28:14241441.

Bozo O, Tunca A, Simşek Y. The effect of death anxiety and age on healthpromoting behaviors: a terror-management theory perspective. J Psychol 2009;143:377-389.

Dolezal BA, Neufeld EV, Boland DM, Martin JL, Cooper CB. Interrelationship between sleep and exercise: a systematic review. Adv Prev Med 2017;2017:1364387.

Mayolas-Pi C, Simón-Grima J, Peñarrubia-Lozano C, Munguía-Izquierdo D, Moliner-Urdiales D, Legaz-Arrese A. Exercise addiction risk and health in male and female amateur endurance cyclists. J Behav Addict 2017;6:74-83.

Michael K, Ben-Zur H. Risk-taking among adolescents associations with social and affective factors. J Adolesc 2007;30:17-31.

Nakamura T. The integration of school nutrition program into health promotion and prevention of lifestyle-related diseases in Japan. Asia Pac J
Clin Nutr 2008;17 Suppl 1:349-351.

Nogueira A, Molinero O, Salguero A, Márquez S. Exercise addiction in practitioners of endurance sports: a literature review. Front Psychol 2018;9:1484.

Proudfoot NA, King-Dowling S, Cairney J, Bray SR, MacDonald MJ, Timmons BW. Physical activity and trajectories of cardiovascular health indicators during early childhood. Pediatrics 2019;144:e20182242.

Scanlan TK, Carpenter PJ, Schmidt GW, Simon JP, Keeler B. An introduction to the sport commitment model. J Sport Exerc Psychol 1993;15: $1-15$.

Tamura A, Shimura K, Inoue Y. A survey of health awareness and physical activity among Japanese undergraduate rehabilitation students. J Phys Ther Sci 2021;33:106-111.

Woolf K, Reese CE, Mason MP, Beaird LC, Tudor-Locke C, Vaughan LA. Physical activity is associated with risk factors for chronic disease across adult women's life cycle. J Am Diet Assoc 2008;108:948-959. 